\title{
Why people prefer seeking care from one country to other countries: a case study from Cambodia
}

\begin{abstract}
Medical tourism is attracting attention of travelers from all over the globe. Globalization and advances in technology have transformed health care in the past decade; but generally, the process of providing care in developing countries is often poor and varies widely. Patients travel from one country to another countries with many influent factors; patients might search for the highest possible quality of health care, whereas others might be looking for less expensive treatment abroad. This paper reviews relevant literatures to show factors to cause the medical tourism and challenges of healthcare in Cambodia, especially, the main motivations of patients to seek medical treatment abroad.
\end{abstract}

Keywords: Cambodian patients, healthcare, medical tourism, quality, seeking healthcare
Volume 6 Issue 4 - 2017

\author{
Hai Marady, Xu Huaifu \\ Department of Business Management, China Pharmaceutical \\ University, China

\begin{abstract}
Correspondence: Xu Huaifu, School of International Pharmaceutical Business. China Pharmaceutical University (CPU). \#639 Longmian Avenue, Jiangning District. Nanjing, 2III98 China. Tel (+86)2586185423. Email haimarady@gmail.com
\end{abstract}

Received:September 13, 2017 | Published: November 06 2017

\section{Introduction}

The current global trend towards a more integrated world is challenging our understanding of public health. As national borders become increasingly porous, public health experts need to explore new ways of managing national health systems. Individuals have travelled abroad for health benefits since ancient times, and during the $19^{\text {th }}$ Century in Europe for example there was a fashion for the growing middle classes to travel to spa towns to 'take the waters', which were believed to have health-enhancing qualities. During the $20^{\text {th }}$ Century, wealthy people from less developed areas of the world travelled to developed nations to access better facilities and highly trained medics. However, the shifts that are currently underway with regard to medical tourism are quantitatively and qualitatively different from earlier forms of health related travel. People travelling abroad with the expressed purpose of accessing or receiving medical treatment is a growing phenomenon associated with processes of globalization. This includes cheaper and more widely available air travel and cross-border communication through the internet, which allows medical providers from one country to market themselves to patients in another. There is growing recognition that increased demand for services among users is related to improved quality and accountability by the health care system, and empowerment of patients and respectful treatment. Health workforce capability is limited by numbers and expertise. There are the conventional reasons why Southeast Asians are travelling for healthcare: cost, shorter wait times for procedures, access to treatments unavailable in one's home country and the added bonus of cheap travel. But sometimes people are travelling for medical care simply because they have no other choice. Medical tourism has actually a lot more direct and indirect benefits, and they all depend on the circumstances of your travel. The far less serious your condition is, the more you will have a better time being treated in foreign land. There are always some negative things to consider, but generally, the benefits-affordability, quality of healthcare, availability of services, and the opportunity to travel-far outweigh any of the disadvantages.

\section{Literature review}

\section{What is medical tourism?}

The trade in health services for foreign patients, often termed 'medical tourism' or medical travel, is a growing industry being aggressively marketed across Asia. Medical tourism has become a US $\$ 60$ billion a year business and is growing by $20 \%$ a year. Experts predict businesses and governments in developed countries will join the trend, "outsourcing" medical services to low cost providers abroad. Anyway, the global growth in the flow of patients and health professionals as well as medical technology, capital funding and regulatory regimes across national borders has given rise to new patterns of consumption and production of healthcare services over recent decades. A significant new element of a growing trade in healthcare has involved the movement of patients across borders in the pursuit of medical treatment and health; a phenomenon commonly termed 'medical tourism'. Medical tourism occurs when consumers elect to travel across international borders with the intention of receiving some form of medical treatment. Medical tourism can be defined as the process of traveling outside the country of residence for the purpose of receiving medical care. Growth in the popularity of medical tourism has captured the attention of policy makers, researchers and the media. Originally, the term referred to the travel of patients from less developed countries to developed nations in pursuit of the treatments not available in their homeland. ${ }^{1}$ Medical tourists cross national border to access care, motivated by health service issues such as high cost, lengthy wait time and/or lack of accessibility in their home system..$^{2-4}$

\section{The flow of health care seekers around the world}

The current global trend towards a more integrated world is challenging our understanding of public health. In recent years, more and more patients have decided to seek medical treatment in countries where they are not resident for better healthcare system. For years tourists from developed countries have been jumping on planes and 
heading out to less well-off countries in order to save money on medical procedures that cost many times more in their own countries. In some cases they simply spend the same amount of money but enjoy three or four weeks convalescing in a warm climate. Globally, medical tourism is huge, and Southeast Asia is an industry hotspot. Patients Beyond Borders, a US-based organization that tracks trends in medical tourism worldwide, estimates that the global market is expanding by up to $25 \%$ each year and is worth upwards of $\$ 55$ billion annually with more than 11 million consumers-nearly a third of whom are travelling to Southeast Asia. Every year, Indonesians leave their country in droves to access basic medical services they can't find in their own country. According to media reports, the Indonesian government estimates that its citizens spend roughly $\$ 11.5$ billion a year on healthcare abroad-much of it in Malaysia. However, it's not just Indonesians who are traversing the region to seek medical care they cannot find at home. ${ }^{5}$ Due to a lack of trust in local healthcare facilities, thousands of Cambodians spend millions of dollars a year on health tourism-going to countries like Thailand, Vietnam or Singapore for treatment. ${ }^{6}$ The number of Cambodian outbound tourists reached some $1,400,000$ in 2016 up from 1,200,000 the previous year. The visitors from $24 \%$ to $30 \%$ travelled to Thailand and Vietnam for visit and medical check-up purpose. Cambodian tourist spent approximately US\$600million dollars a years during their oversee trips. ${ }^{7}$ While most would think that medical travelers seek cheap and fast medical attention, some facts in a May 2008 McKinsey and Company report regarding medical tourism indicated otherwise. The report states that $40 \%$ of medical travelers seek the world most advanced technology; they search for high quality medical care global, giving little attention to the proximity of potential destinations or the cost of cares. $32 \%$ seek better healthcare than they could find in their own countries, which are often in the developing world. Another $15 \%$ seek for faster medical services while only $9 \%$ of travelers seek lower costs as their primary consideration (Figure 1). ${ }^{8,9}$

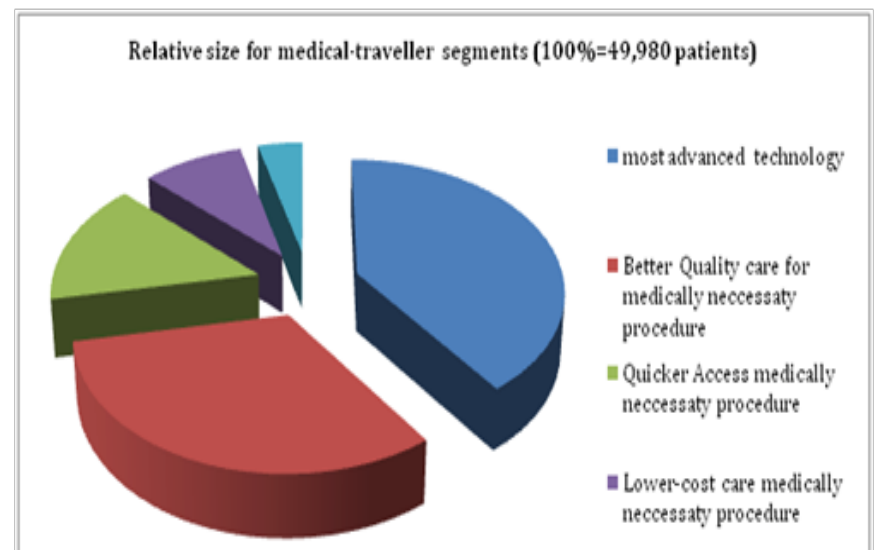

Figure I Medical tourism drivers.

\section{Factors to encourage patients going to better countries for treatment}

New developments in information technology have facilitated access to information about foreign health providers. Globalization has lowered transportation costs and reduced language barriers. Trade liberalization efforts in services are another driving force of enhanced medical travel. Patients explore options beyond borders due to dissatisfaction with their domestic health system, such as the unavailability of appropriate treatments, relatively low quality of care, absence of modern technology and/or shortage of healthcare providers. Many well-funded patients travel to countries with a long tradition of receiving foreign patients, others might decide to seek care in countries that have recently upgraded their health sector through new and better equipped hospitals as well as well trained professionals. Some patients looking for more affordable health care might also travel to neighboring countries that offer health services of similar quality but at a significantly lower price. Such patient movements are often facilitated by health systems that are becoming more and more integrated. Jagyasi gave five major "factors" involved in decision making: affordable, accessible, available, acceptable and additional. ${ }^{10}$ Affordable is probably the major reason and this is particularly true for patients from the well-off, developed countries like America and UK, where private health care is expensive, and some surgeries are not covered by their insurance. Available is often because the medical treatment they need is not available in their local areas or not trusted by the patients, as is often the case with Omani patients. Accessible applies more particularly to patients from countries where the waiting list is long, particularly to National Health Service patients in the UK and in Canada. In the UK, private health care may be available locally, but is expensive. Acceptable applies to services, which may be affordable, available, and accessible, but they are not acceptable in the patient's own country for religious, political reasons or other social reasons. Additional refers to the availability of better care, perhaps better technology, or a better specialist, or simply better service and personalized care abroad compared to care in the home country. According to the above five factors, the quality of Cambodian's healthcare is completely low than other countries in the region.

\section{Healthcare in Cambodia}

The Cambodian society has suffered from decades of international conflict, and especially from the 1975-1979 Khmer Rouge government. To create a so-called egalitarian socialist rural society and to destroy the past, cities were evacuated, formal health care and education abandoned, and money abolished. ${ }^{11}$ After the Paris Peace Accords and 1993 elections, Cambodia has gradually become more stable and peaceful. The country is beginning to recover from its loss of qualified human resources and the destruction of its infrastructure. Facing the challenge of rebuilding the health system while having to coordinate extensive foreign aid contributions, ${ }^{12}$ the Cambodian Ministry of Health $(\mathrm{MoH})$, heavily supported by the donor community, has been implementing a Health Coverage Plan since 1996. The bulk of the development is occurring in the urban economy and disparities are growing in the distribution of income. ${ }^{13}$ Currently Cambodia has 0.23 physicians per 10,000 of the population, ranking 148 out of 192 countries. The current life-expectancy of Cambodia is 62.67years (60.31 for men and 65.13 for women), ranking as 177 out of 192 countries. ${ }^{14}$ As a result of the low number of physicians per capita and the highly rural population, the people of Cambodia face further barriers to health services due to both infrastructural and geographical barriers. Cambodia's health indicators are largely superior to other low-income countries, but still lag significantly behind its neighbors in the South East Asia region. ${ }^{15}$ Despite these classifications, literature on the Cambodian health system is not well-defined in such boxes. Studies, interventions, and innovations that have been underway are multifaceted as the challenges faced by the Cambodian health system are complex and interdisciplinary. ${ }^{16}$ Cambodian healthcare is in the midst of a transition from providing basic services to a modern system capable of treating specialized cases. Patients will find facilities 
that can take care of their daily needs, but may still have to travel outside the country (in some cases) for specialized care. Healthcare in Cambodia still facing many key areas of concern : lower aggregate health indicators than neighboring countries, despite higher per capita health spending; low public service wages creating a situation of low service delivery in the public health services; a continued shortage of key medical personnel; financial barriers remain for significant proportions of the population; significant lack of accountability within the financing of the health system, posing major challenges to the planning of efficient resource allocation; and external aid remains fragmented and is not always in line with national health priorities. ${ }^{17}$

\section{Methodology}

In this article the findings of a scoping review are presented that address the question: why patients prefer seeking healthcare outside the country? Academic articles, grey literature, and media sources were gathered in a comprehensive fashion in order to answer this question. This is consistent with the scoping review approach, which aims to synthesize what is known about a particular issue across multiple literature types in order to achieve clarity about the state of knowledge and evidence that exists. ${ }^{18}$ The synthesis presented here follows the scoping review protocol outlined by Arksey et al., ${ }^{19}$ identifying the question; identifying relevant literature; selecting the literature; charting the data; and collating, summarizing and reporting the results. In the remainder of this section the steps undertaken to complete each stage are outlined. The study is conducted from 2016 to 2017, by reviewing and analyzing the documents and data from the interviewee. The interviewee was randomly selected in local and outside the county.

\section{Findings}

According to the documents and literature analysis, i found that Cambodia still needs a highly skilled professional health care workforce to address the country's significant health challenges. Ozawa et al., ${ }^{20}$ have shown that the popular view of quality of care by public and private providers in Cambodia relates to waiting time, perceived costs, effectiveness and availability of medicine, mode of administering medicines and interpersonal skills displayed by medical personnel. Among the users of the public health services, many complain about lack of hygiene and high cost. ${ }^{21}$ Anecdotal evidence suggests that services provided by the private sector are often unnecessarily expensive and of questionable quality. ${ }^{22,23}$ An increasing number of patients are seeking care abroad, mainly in neighboring countries such as Thailand and Viet Nam. Most hospitals lack modern trauma units or services such as ambulances with trained medics. Local hospital staff may be able to stabilize patients, but a serious accident will require an evacuation to Bangkok by helicopter or car. The safety of blood transfusions also varies from hospital to hospital, and should be avoided outside of Phnom Penh. Despite this challenge, Cambodian doctors-particularly specialists-are gradually catching up with their counterparts elsewhere in Asia, says Park, who also heads the Cambodia Neurosurgery Support Project to train local neurosurgeons. The figure below show the comparison of healthcare among ASEAN countries, not surprisingly, higher-income countries are well-ahead of the lower-income ones in terms of resource availability for health, healthcare coverage and quality of care (Figure 2 ). The numbers of Cambodian going to Vietnam for healthcare has increased $20 \%$ in the first half of 2015 , according to the official figure from Ministry of tourism. They are going to Vietnam because they can find a wider range of services and the quality is better than home country. ${ }^{24}$ Anyway, according to Taikry ${ }^{25}$ said that "there are not enough human resources and hospitals, though we have the same standard. The medical services and hospitals in Cambodia do not meet international standards and lack hands-on training of advanced practical applications by medical professionals. ${ }^{26}$ The randomly selected of interviewer mentioned that, the medical practice is still poor, doctors usually appear arrogant and wouldn't tell patients why they would prescribe certain medicines to them, the cost of treatment is expensive. ${ }^{27}$
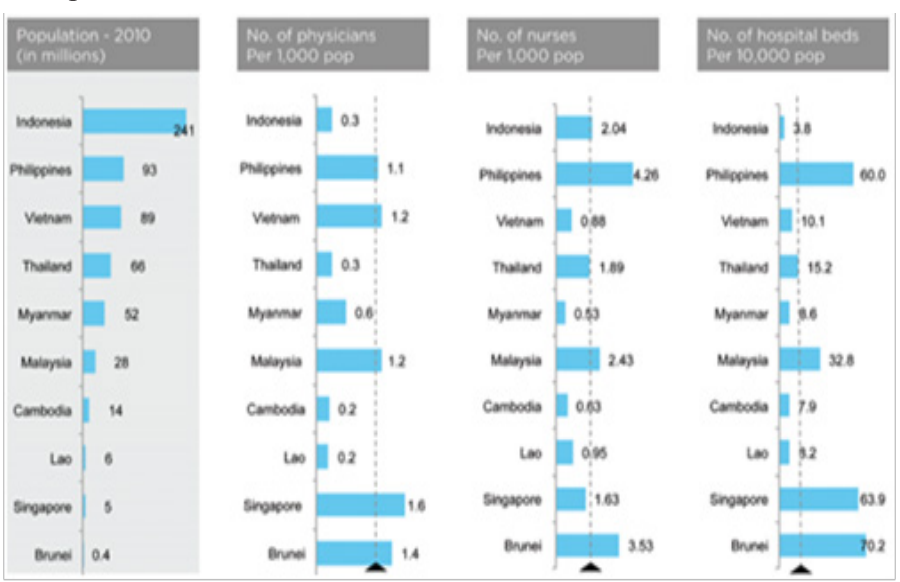

Figure 2 Population and healthcare resource comparison across ASEAN.

\section{Conclusion and recommendations}

Many factors appear to influence the movement of people for better healthcare services, such as lack of highly skilled professional health care workforce to address the country's significant health challenges, waiting time, perceived costs, effectiveness and availability of medicine, mode of administering medicines and interpersonal skills displayed by medical personnel, lack of hygiene and high cost, lack of modern trauma units or services such as ambulances with trained medics etc. The medical services and hospitals in Cambodia do not meet international standards and lack hands-on training of advanced practical applications by medical professionals. Hence an increasing number of patients are seeking care abroad, mainly in neighboring countries. Medical tourism is challenging the traditional ways of thinking about public health and we are confronted with a wide array of questions that still need to be answered. Research about the topic is still in its infancy and more studies are urgently needed. The concept of medical tourism is appealing to anyone who is interested in high quality and affordable healthcare. The medical tourism phenomenon is gaining popularity and the number of people going abroad for treatment increases rapidly every year. With many medical tourism benefits, advancements in technology and improvements in healthcare standards within developing countries, it is likely that the advantages of medical tourism will provide a striking economical solution to many healthcare problems.

\section{Acknowledgements}

None.

\section{Conflict of interest}

Author declares that there is no conflict of interest. 


\section{References}

1. Tomislav M. What is Medical Tourism? NEWS: Medical Life Sciences, $\mathrm{UK} ; 2017$.

2. Ehrbeck T, Guevara C, Mango PD, et al. Healthcare and the consumer. McKinsey Quaterly, Cambodia; 2008. p. 80-81.

3. Leahy A. Medical Tourism: The impact of travel to foreign countries for healthcare. Surgeon. 2008;6(5):260-261.

4. Horowitz MD, Marsek P, Mohanasundaram S, et al. Why in the world do patients travel for healthcare? Asia Pac Biotech News. 2008;12(7):24-28.

5. Logan Connor. Region's medical tourism boom fuelled by Southeast Asians. GLOBE, Cambodia; 2016.

6. Building Trust in local doctors and Health care. Khmer Times, Cambodia; 2016.

7. 2016: 1.4 Million Cambodian Tourists Travel Abroad. Agence Kampuchea Presse, Cambodia; 2017.

8. Medical Tourism. HOPE: European Hospital and Healthcare Federation. Europe; 2015. p. 1-41.

9. Tilman E, Ceani G, Paul D Mango. Mapping the market for medical travel. The McKinsey Quarterly, USA; 2008. p. 1-11.

10. Jagyasi P. Defining Medical Tourism-Another Approach. Medical Tourism Magazine, USA; 2008.

11. Chanda N. Brother Enemy-The war after the war: A history of Indochina since the fall of Saigon. Houghton Mifflin Harcourt, USA; 1986. p. $1-478$.

12. Lanjouw S, Macrae J, Zwi AB. Rehabilitating health services in Cambodia: the challenge of coordination in chronic political emergencies. Health Policy Plan. 1999;14(3):229-242.

13. Annear P. Developing a strategy for social health protection in Cambodia: In Promoting Sustainable Strategies to Improve Access to Health Care in the Asian and Pacific Region. Cambodia; 2009. p. 1-36.
14. The World Fact book: Cambodia. Central Intelligence Agency, USA; 2013.

15. Health Systems 20/20. Health System Report: Cambodia; 2012.

16. Gilson L. Health Policy and Systems Research: A Methodology Reader. Switzerland: World health organization; 2012. p. 1-474.

17. Lane C. Scaling Up for Better Health in Cambodia. World Health Organization \& Ministry of Health, Kingdom of Cambodia, Switzerland; 2007. p. 1-52.

18. Davis K, Drey N, Gould D. What are scoping studies? A review of the nursing literature. Int J Nurs Stud. 2009;46(10): 1386-1400.

19. Arksey H, Malley L. Scoping studies: Towards a methodological framework. Int J Soc Res Method. 2005;8(1): 19-32.

20. Ozawa S, Walker D. Comparison of trust in public vs private health care providers in rural Cambodia. Health Policy Plan. 2011;26(Suppl 1):i20 i29.

21. Eng P, Depasses JP. National client satisfaction survey: Healthcare services at public health facilities. Ministry of Health, Cambodia; 2012. p. $1-79$.

22. Rose G, Dixon S, Kiry LV, et al. Private practitioners in Phnom Penh: a mystery client study. Philippines: World Health Organization; 2002.

23. Gollogly L. The dilemmas of aid: Cambodia 1992-2002. Lancet. 2002;360(9335):793-798.

24. Vietnam attracts Cambodian medical tourists. International Medical Travel Journal. Cambodia; 2015.

25. Abby S. Poor Health Care Facilities Push People Abroad. The Cambodia Daily, Cambodia; 2009.

26. Norodom S. Cambodia's medical care lacks international standards. The Phnom Penh Post, Cambodia; 2012.

27. Chan Sophal. Health care problems in Cambodia. Campro Post, Cambodia; 2011. 